\title{
Rarecase of biventricular thrombi complicating pulmonary embolism
}

\author{
Mark Mujer, ${ }^{\oplus}$ Samanjit Kaur Kandola, Yehia Saleh, ${ }^{\circledR}$ Khader Herzallah
}

Michigan State University, East Lansing, Michigan, USA

\section{Correspondence to Dr Mark Mujer, mark.mujer@hc.msu.edu}

Accepted 18 April 2019

\section{DESCRIPTION}

A 70-year-old man with a history of chronic lymphocytic leukaemia (CLL) in remission, hypertension, dyslipidaemia and active smoking presented with a 2-week history of non-productive cough, progressive shortness of breath and right lower extremity swelling.

On presentation, the patient was tachypnoeic with a respiratory rate of 24 breaths $/ \mathrm{min}$. Initial $\mathrm{O}_{2}$ saturation was $89 \%$ on room air. Blood pressure and heart rate were within normal range. Physical examination showed decreased breath sounds bilaterally, an audible $\mathrm{S} 3$ at the apex and +2 bipedal oedema. Initial laboratory work-up was remarkable for a brain natriuretic peptide of $1800(0-100 \mathrm{pg} / \mathrm{mL})$, troponin $0.26(0.00-0.03 \mathrm{ng} / \mathrm{mL})$ and potassium $3.1 \mathrm{meq} / \mathrm{L}$. Initial ECG showed sinus rhythm with ventricular premature complexes and $\mathrm{Q}$ waves in V1-V2 unchanged from previous ECGs. Due to his right leg pain, Doppler ultrasonography of the right lower extremity was ordered, which showed a deep venous thrombosis in the right popliteal vein. CT pulmonary angiogram of the chest showed a filling defect in the right main pulmonary artery extending into the upper lobe pulmonary arteries (figure 1). Small filling defects were also seen on the left lower lobe arterial branches suggestive of multiple pulmonary emboli (PE). Interestingly, a right ventricular filling defect consistent with right apical ventricular thrombus was also seen on imaging (figure 2).

The patient was started on subcutaneous enoxaparin $1 \mathrm{mg} / \mathrm{kg}$ two times per day. Transthoracic echocardiogram (TTE) showed new-onset severe cardiomyopathy with an ejection fraction (EF) $<20 \%$, a large fixed thrombus on the apical

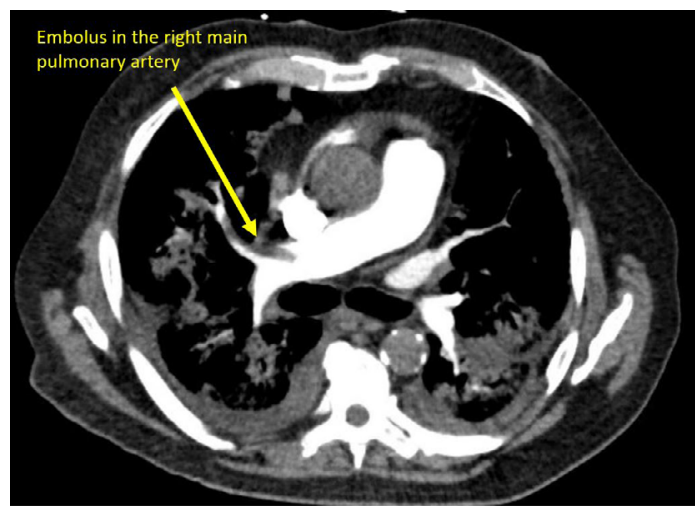

Figure $1 \mathrm{CT}$ angiography of the chest showing a filling defect in the right main pulmonary artery, which extends into the upper lobe pulmonary arteries.

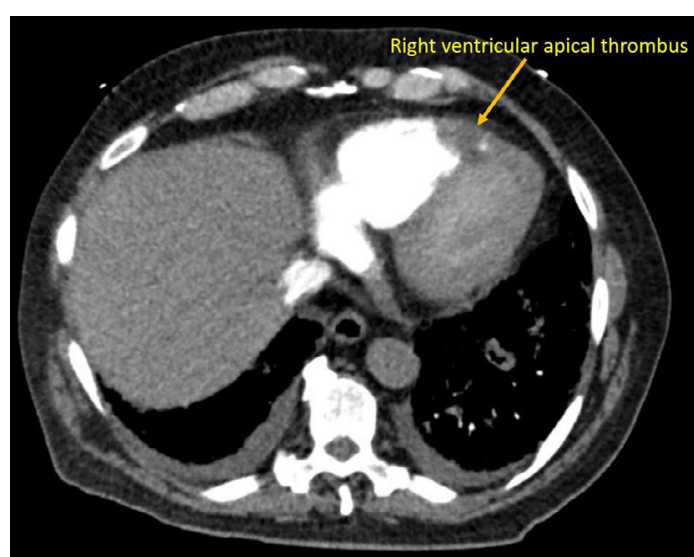

Figure 2 CT angiography of the chest showing a right ventricular filling defect consistent with right apical ventricular thrombus.

wall of the left ventricle and a right ventricular apical thrombus (videos 1-3, figures 3 and 4).

Troponin increased to $0.30 \mathrm{ng} / \mathrm{mL}$. Subsequently, the patient underwent cardiac catheterisation, which showed $100 \%$ occlusions of both the left anterior descending artery and the right coronary artery but with collateral circulation (videos 4 and 5). A decision was made not to proceed with coronary artery bypass surgery due to medical risks and the patient was managed medically with aspirin, carvedilol and lisinopril. He was subsequently placed on rivaroxaban and discharged in a stable condition. He was seen in the outpatient clinic 3 months later and a repeat TTE showed a dilated left ventricle, EF 25\%-30\% and no evidence of the intracardiac thrombi. Patient was then referred for implantable cardioverter defibrillator placement.

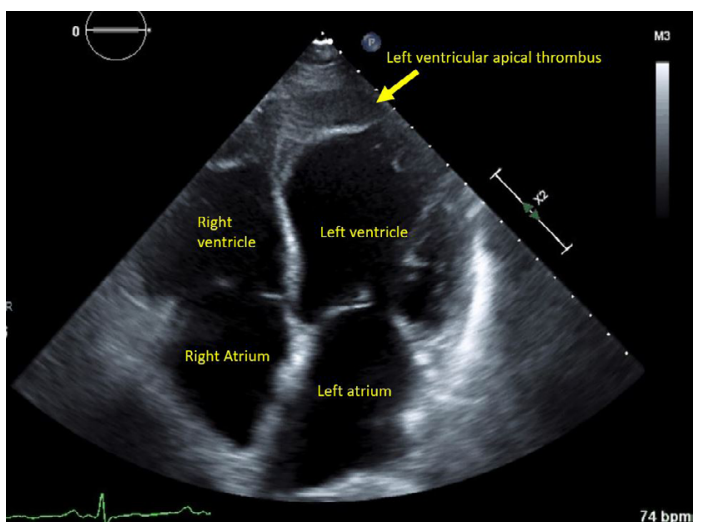

Figure 3 Transthoracic echocardiogram in apical fourchamber view showing a left ventricular apical thrombus. 
Images in...

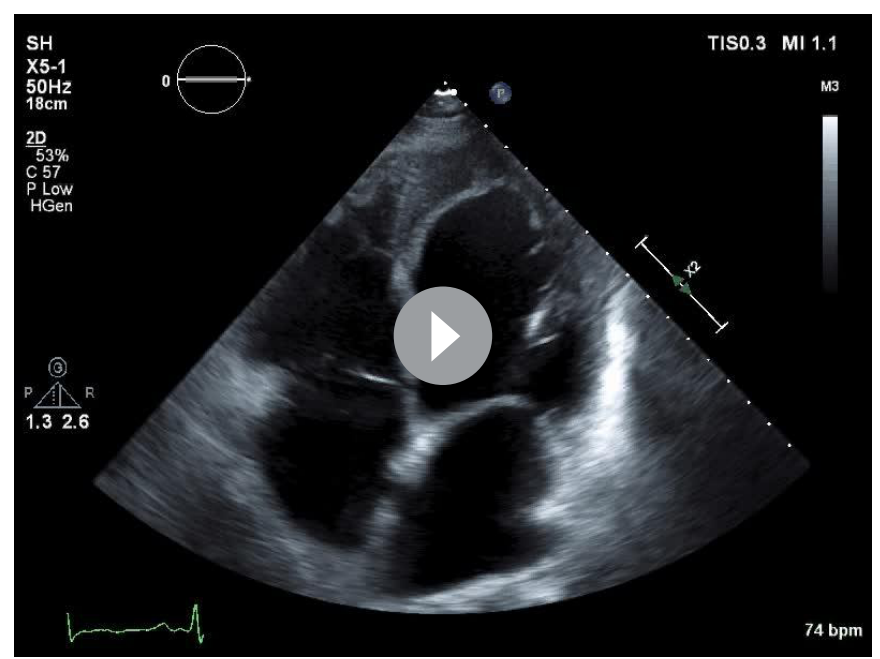

Video 1 Transthoracic echocardiogram in apical four-chamber view showing reduced biventricular systolic function, with visible apical thrombi in both ventricles.

Isolated ventricular thrombus formation is a well-described complication of cardiomyopathy with an EF $<35 \%$. Stasis from ventricular dysfunction can result in the formation of intramural thrombus. The formation of biventricular thrombi is an uncommon occurrence and its detection with imaging studies is rare. Biventricular thrombi are more common in patients with hypercoagulable states such as heparin-induced thrombocytopenia and antiphospholipid antibody syndrome. Biventricular thrombi have also been reported in cases of myocardial infarction, HIV-induced cardiomyopathy, Takotsubo cardiomyopathy, myocarditis and peripartum cardiomyopathy. In our case, hypercoaguable work-up was remarkable for elevated homocysteine levels. Elevated homocysteine levels, along with a history of CLL, and concurrent cardiomyopathy predisposed our patient to these thromboembolic events.

Echocardiogram can document underlying wall motion abnormalities and characterise the thrombi to evaluate the risk of embolism. Larger, more mobile or freely floating thrombi have a higher risk of embolisation. If TTE with contrast is

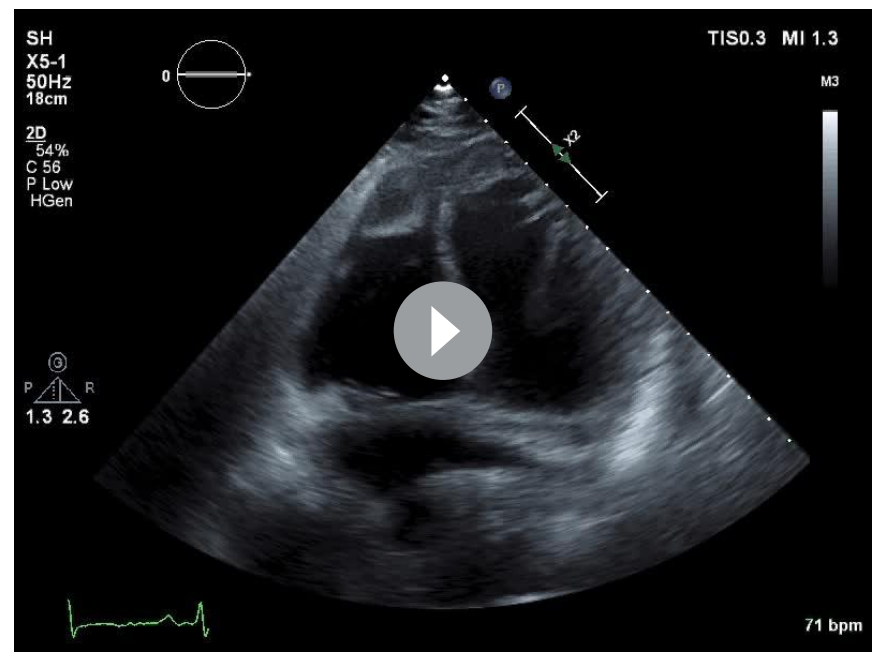

Video 2 Transthoracic echocardiogram in modified apical fourchamber view showing reduced biventricular systolic function, with visible right ventricular apical thrombus.

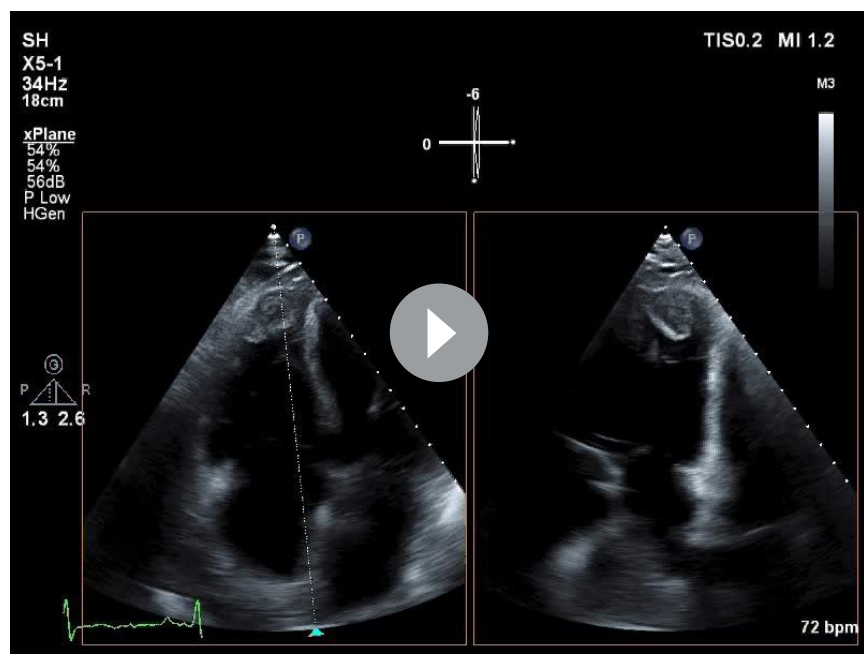

Video 3 Transthoracic echocardiogram in biplane view showing a right ventricular thrombus.

contraindicated or further evaluation is necessary, cardiovascular magnetic resonance with gadolinium contrast may be considered.

There are no medical guidelines on the treatment of biventricular thrombi in the existing literature. Common practice involves heparinisation followed by anticoagulation. In patients with a single left ventricular thrombus after an ST-elevation myocardial infarction, the European Society of Cardiology recommends the use of oral anticoagulation (OAC) for up to 6 months, guided by echocardiogram monitoring and evaluation of concomitant need for antiplatelet therapy. ${ }^{1}$ The American College of Cardiology Foundation/American Heart Association recommends starting patients on an OAC in addition to dual antiplatelet therapy, but no specific duration of anticoagulation is recommended. ${ }^{2}$ So far, the only approved $\mathrm{OAC}$ in management of left ventricular thrombi is warfarin; however, several case reports and series reported promising results using direct OACs.

Any patient presenting with an acute pulmonary embolism should be risk stratified and evaluated for possible thrombolysis. There is an absence of clear data in literature with regards to when a single ventricular thrombus complicates pulmonary embolism, more so that of a biventricular thrombi. As such, the

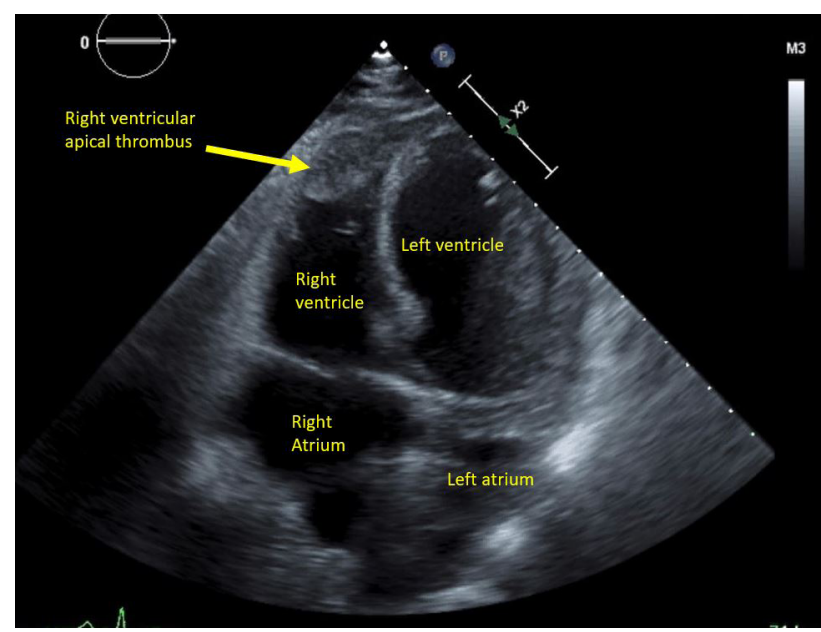

Figure 4 Transthoracic echocardiogram in apical four-chamber view showing a right ventricular apical thrombus. 


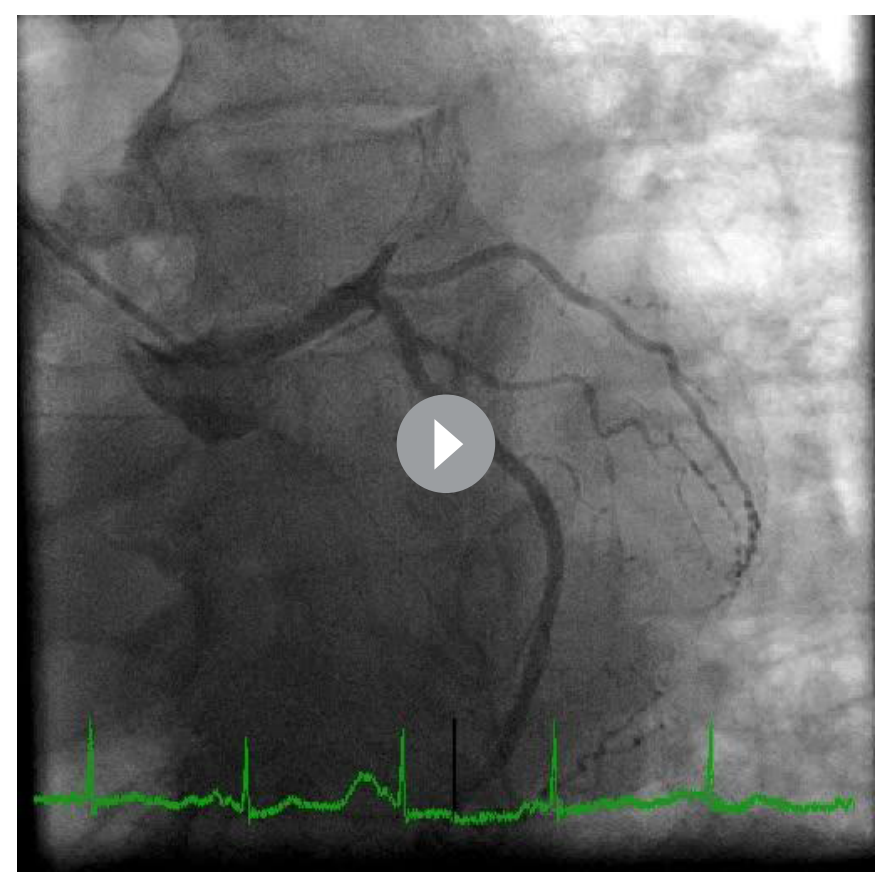

Video 4 Coronary angiogram showing proximal total occlusion of the left anterior descending artery.

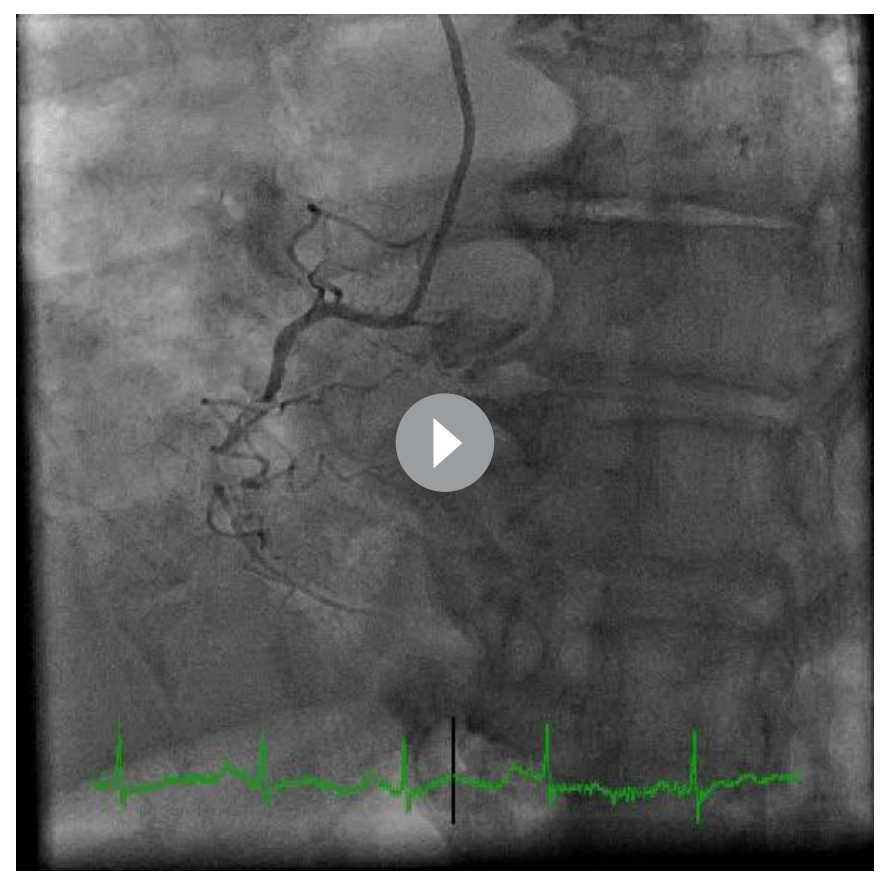

Video 5 Coronary angiogram showing proximal total occlusion of the right coronary artery. approach to each patient should be individualised. In our case, the patient presented with haemodynamically stable PE and bilateral ventricular thrombi. The thrombi were located in the akinetic left and right ventricular apices, hence it had low risk of embolisation. In addition, thrombolytic therapy in the setting of a left ventricular apical thrombi can lead to catastrophic sequelae due to the high risk of secondary embolisation to the systemic circulation. Therefore, medical management was sought with the use of enoxaparin followed by OAC with rivaroxaban. Thrombectomy should be considered in patients with thrombi features deemed to be high risk for embolisation. Fibrinolysis may result in embolisation from the lysed thrombus and is therefore not recommended. ${ }^{4}$

Patients should be followed with repeat imaging to document thrombi clearance 1-3 months after the initial identification and treatment. Findings during this period should guide clinicians on the duration of anticoagulation. Multiple factors should be included in the decision for extended anticoagulation including resolution of thrombi, hypercoagulability, presence of peripheral thrombosis and the risk of bleeding.

\section{Learning points}

- There are neither medical guidelines nor sufficient data on the management of biventricular thrombi in existing literature but common practice involves heparinisation followed by oral anticoagulation.

- Repeat imaging studies within 1-3 months should be done to detect dissolution of thrombi and to guide clinicians on the length of anticoagulation.

Contributors MM and SKK created the initial manuscript. YS obtained and read the images. $\mathrm{KH}$ revised the manuscript.

Funding The authors have not declared a specific grant for this research from any funding agency in the public, commercial or not-for-profit sectors.

Competing interests None declared.

Patient consent for publication Obtained.

Provenance and peer review Not commissioned; externally peer reviewed.

\section{REFERENCES}

1 Ibanez B, James S, Agewall S, et al. 2017 ESC Guidelines for the management of acute myocardial infarction in patients presenting with ST-segment elevation: The Task Force for the management of acute myocardial infarction in patients presenting with ST-segment elevation of the European Society of Cardiology (ESC). Eur Heart $J$ 2018;39:119-177.

2 O'Gara PT, Kushner FG, Ascheim DD, et al. 2013 ACCF/AHA Guideline for the Management of ST-Elevation Myocardial Infarction. J Am Coll Cardiol 2013:61:e78-140.

3 Abdelnaby M, Almaghraby A, Abdelkarim 0, et al. The role of rivaroxaban in left ventricular thrombi. Anatol J Cardiol 2019;21:47-50

4 Szymczyk E, Lipiec $P$, Kasprzak J. Massive intraventricular thrombi in a previously healthy 43-year-old male. Eur J Echocardiogr 2009;10:989-90. 
Images in...

Copyright 2019 BMJ Publishing Group. All rights reserved. For permission to reuse any of this content visit https://www.bmj.com/company/products-services/rights-and-licensing/permissions/

BMJ Case Report Fellows may re-use this article for personal use and teaching without any further permission.

Become a Fellow of BMJ Case Reports today and you can:

- Submit as many cases as you like

- Enjoy fast sympathetic peer review and rapid publication of accepted articles

Access all the published articles

- Re-use any of the published material for personal use and teaching without further permission

For information on Institutional Fellowships contact consortiasales@bmjgroup.com

Visit casereports.bmj.com for more articles like this and to become a Fellow 